\title{
REVISING STRATEGIES FOR DIFFERENT TEXT TYPES
}

\author{
J. Y. Roussey, A. Piolat and F. Guercin
}

Centre de Recherche PsyCLE, Université de Provence, 29, avenue

Robert Schuman, 13621 Aix-en-Provence Cedex, France

\begin{abstract}
Forty-eight children and forty-eight adults of contrasting degrees of expertise made a series of corrections in order to improve a text (narrative or description) in which three within-statement errors and three between-statement errors had been inserted. Subjects used a simplified word processor (SCRIPREV) which recorded all movements of linguistic units. The purpose of this research was to study revising strategies by examining the correction-sequencing procedures implemented by these subjects. The procedures, which were coded in the form of time series, were compared to the time series of model revising procedures (i.e. effective ones) representing three strategies based on certain predefined functional principles (linguistic level, execution order). The adults used two of these strategies: the Simultaneous Strategy for the narrative, and the Local-thenGlobal Strategy for the description. The children used the Local-then-Global Strategy for the narrative, but did not use any identifiable procedure to revise the description, which they did not manage to totally improve in the expected manner.
\end{abstract}

\section{Introduction}

Learning to write necessarily involves learning how to improve one's text. In order to help learning writers, psychologists must understand how they proceed. The aim of the present study was thus to analyse the sequence of operations performed by writers of varying ages and degrees of expertise as they gradually make a series of corrections of different linguistic levels spread throughout an experimental text.

In order to do this, we must be able to describe the procedures used in making such a series of corrections. This in turn involves clearly stating the functional principles underlying those procedures. The term 'strategy' will be used here to refer to the selection and execution of a correction ordering procedure founded on such functional principles, themselves based on the given state of the reviser's knowledge.

The text revising model proposed by Hayes, Flower, Schriver, Stratman \& Carey (1987) is clearly more complex than the initial models of this process (see, for example, Hayes \& Flower, 1980; Scardamalia \& Bereiter, 1983). In the new model, the comprehension and production processes necessarily involved in 
improving the product being composed are finely broken down into a series of sub-processes. Regardless of the scope or linguistic level of the correction to be made, the authors clearly make the distinction between two aspects of each subprocess: its nature, and the knowledge it affects or generates. At the onset of the revising activity, during the task definition process, the task goals are set and the constraints and criteria that will guide the text evaluation process are defined. The latter process involves a preliminary test reading of the text aimed at detecting or diagnosing the problem and building a more or less detailed representation of it. This model states that during this initial revising step, the comprehension processes activated by the reviser to understand the text as a whole and to define the problems to be solved at various precise locations in the text make use of knowledge about the topic, audience, text schema, etc. The second step is said to involve the knowledge required to produce a solution by revising or rewriting (means-ends table). The solution chosen by the reviser is 'strategic' in so far as it depends on the degree to which the problem is defined. It consists of modifying the text or the plan (goal and procedures; Flower \& Hayes, 1981).

This model is certainly instrumental for understanding the differences in the performance of subjects of varying ages and degrees of expertise. However, the effects of different types of knowledge on how different types of writers execute the task should be determined. Although in this model, Hayes et al. (1987) accurately define the various processing steps required for successful revision, they do not include one important dimension of the activity: the recurrence of the processing operations. The model only predicts that the sequence of processes is repeated once for each correction to be made, but it does not deal with the cognitive difficulties that might be incurred by the reviser.

Indeed, revisers must control a linguistic object whose complexity takes on several dimensions (Piolat, 1988). A text is not a simple juxtaposition of statements that the writer must process individually. It is structured into different linguistic levels, such as the micro-structural level (lexicon, syntax) and macro-structural level (text schema, semantic organisation of information; see Beaugrande, 1984; van Dijk, 1984). The various levels do not operate autonomously, but instead are interdependent and necessarily integrated. Thus, the corrections a reviser must make may differ in both format and nature. For example, local modifications may have repercussions on the overall architecture of the text. In other words, since a given local correction may affect the improvement plan of the entire text, it must be possible to incorporate it into this plan for it to be an appropriate correction. Furthermore, the writer is faced with the necessity of producing several temporally ordered revisions pertaining to problems spread throughout the text, and therefore, here again, he/she must be sure of the compatibility of the corrections made.

As such, the text improvement process is a cognitively complex one requiring the execution of a series of sub-tasks in succession, each one contributing to attaining the final goal: the finished text. The writer must make a series of corrections in a given order, a process which in itself constitutes a cognitive problem (Piolat, Roussey \& Guercin, 1988). 
Our method of determining what correction sequencing strategies are used by revisers is as follows. (a) Define, a priori, some of the potential functional principles underlying revision, and then some hypothetical problem-solving strategies based on those principles. (b) Translate these strategies into concrete action sequences or model time series; also translate the performance of revisers into actual time series. (c) Compare the distance between the model time series and the actual time series, and attribute each reviser with the strategy closest to the one he or she actually used in revising.

Two functional principles are defined: text processing order and linguistic-level focusing.

First principle: text processing order

To order the series of corrections to be made in a text, revisers can proceed in a variety of ways. They can correct in a random manner, thus running the risk of missing some of the problems. In this case, 'spot checking' is necessary in order to catch missed errors. On the other hand, the spatial organisation of texts (their clearly distinguishable beginning and end, highly restricted linearisation of words) could be used as a guide for thorough filtering and verification. The search for incongruities and incoherencies and the resulting corrections could be done more efficiently if the text were processed in its order of occurrence.

In other, cognitive tasks with a linear structure (for example, organising the product of two sets), it has been shown that subjects at a very young age do in fact solve this problem by processing the elements in their order of occurrence (Bastien, 1987; Blaye, 1988). We thus can expect even young or non-expert revisers to improve their texts by proceeding in an ordered fashion.

A writer may not always modify a text by starting at the beginning. In this case, in order to continue the task while still applying the functional 'in-order' principle, the reviser must either interrupt processing and start at the beginning, or continue making corrections all the way to the end of the text, then go back to the beginning and continue moving downwards until he/she reaches the starting point.

Second principle: focusing on different linguistic levels

In order to succeed, the writer must control all the linguistic levels of the text, since each level can contain problems and thus may need revising. Results obtained in prior research have shown that revisers of varying ages and degrees of expertise improve the different levels of a text in different ways (Faigley \& Witte, 1981; Fayol \& Gombert, 1987; Piolat, 1990; Witte, 1985). The deepest text levels (the macro-structural aspects) are most often processed by experts only, particularly adults. The fact that the revisions made by young subjects are restricted to the surface level of texts (micro-structural aspects) is thought to stem from their difficulty detaching themselves from their own writing (Daiute, 1986). Young writers' lack of knowledge (or insufficient knowledge) of the overall 
structure of different text types is another possible explanation. The deep level of a narrative, for example, whose standard schema is better known, is more easily improved than that of a description (Piolat, Roussey \& Farioli, 1987).

We may also assume that the on-line processing of a series of problems pertaining to different linguistic levels creates a heavy cognitive overload during text revision. Consequently, even if the writer has the knowledge needed to improve the various linguistic levels of a text, he/she may not succeed at simultaneously focusing on each level in order to make the necessary corrections. In this case, the different levels must be handled one at a time to ensure correction of all aspects of the text. Hayes et al. (1987) speak in this regard of the need for economical management of revising processes whereby the number of passes through the text is pre-determined by the evaluation criteria established at task definition time.

This variable ability of subjects to focus efficiently and simultaneously on one or more linguistic levels constitutes one of the important constraints of correction ordering.

\section{Definition of revising strategies}

If the revising activity is considered to be the successful execution of an overall text improvement plan that incorporates a series of local, functional corrections, the combination of the two hypothetical principles stated above leads us to define three strategies. Indeed, whenever the reviser can simultaneously focus on all linguistic levels, the text can be improved in a single pass (Simultaneous Strategy). On the other hand, if the reviser proceeds in a one-after-the-other fashion, i.e. by consecutive focusing, he/she must go through the text once for each linguistic level to be processed (Local-then-Global and Global-then-Local Strategies). In both simultaneous and consecutive focusing, the more adequate the reviser's knowledge, the better his/her performance.

More specifically, when a writer applies the Simultaneous Strategy (SS), corrections are made in one pass, starting at the beginnning of the text and going through to the end. The writer simultaneously focuses on all the linguistic levels of the text. Consequently, problems of different types are diagnosed and corrected in their order of appearance in the text. When the Local-then-Global Strategy (LGS) is applied, the writer checks and corrects the local linguistic level (microstructure) on the first pass through the text. The global linguistic level (superstructure) is processed during the second pass. Finally, when the Globalthen-Local Strategy (GLS) is used, the writer proceeds in the reverse order, revising at the global level first.

The definition of these hypothetically efficient correction ordering strategies implied that we consider writers to be ideally skilful. They are assumed to (a) construct a representation of the final product that conforms to the expected product, (b) adequately diagnose the linguistic problems in the text, and (c) then correct the problems in an economical way. Thus, the definition of the strategies necessarily takes into account the nature of the problems the subjects must solve in this experiment. Natural revising situations are obviously more complex. 
Nevertheless, if these strategies are actually used, then we can legitimately conclude that the corresponding procedures do incorporate the functional principles essential to performing the revising activity.

\section{Method}

In order to determine whether revisers of differing ages and degrees of expertise use these hypothetical strategies when revising different types of texts, the procedures involved must be formalised. This was done here in terms of sequences of operations performed on the elements in the text. An operation consists of the several text editor manipulations needed to make a correction. The operation sequences were then compared to the successive actions of the subjects.

But we must first make sure that the writers did in fact considerably improve the texts in question, since the strategies defined a priori lead to the elimination of all problems in the text. It would be useless, if not absurd, to expect strategies of this type to be used by revisers who do not manage to sufficiently improve the quality of the text they are revising.

\section{Experimental procedure}

In order to answer the above questions, the data gathered in a prior experiment (Piolat, Roussey \& Farioli, 1987) were analysed in a different manner. In short, the experimental procedure was as follows.

\section{Subjects}

Forty-eight 10-year-old children and 48 adults participated in the experiment. They were divided into two writing expertise levels on the basis of how well they wrote (as assessed by their teachers for the children, and by their level of education for the adults).

\section{Verbal material}

One narrative and one description on the topic of dolphins were generated by the experimenter. These constituted the basic texts, and were the ones the subjects would hopefully produce through revision. Both were very simple and conformed to the standard structure. Each consisted of eight statements into which six perturbing modifications were inserted at two different linguistic levels (see Appendix): the local level (within-statement) and the global level (acrossstatement). At the local level, the syntactic and semantic structure of three of the eight statements was modified so as to lead the reviser to add, delete, or transpose nouns; at the global level, the standard order of the statements was changed so as to encourage the reviser to reorganise the text schema by adding, deleting or transposing statements. 
The revising task

The revising task was done with computer assistance (Piolat, Farioli \& Roussey, 1989). The system (SCRIPREV) was designed to resemble a highly simplified word processor, and allowed the writer to take as much time as he/she needed to modify the text using the verbal material displayed on the screen.

The screen was divided into two areas. The upper, 'text' area contained the experimental text to be revised; the lower, 'save' area, contained several useful or superfluous items. Using an optical pen, the subject was to point to the linguistic segment ( 1 to $\mathrm{n}$ words) that he/she wished to move from the text or save areas, and then indicate the place to insert it in either area (any one of the blanks between two words). After each move, the program justified the text on the screen. All segment moves and locations chosen for insertion were recorded by the SCRIPREV system.

Analysis of data protocol: time series

In order to answer the two questions raised above (were the texts actually improved by the subjects and did they use one of the formalised strategies?), it was necessary to (1) measure the extent to which the revised text resembled the expected text (the basic text, before insertion of errors), and (2) compare the procedures used by the writers with the procedures defined for each hypothetical strategy.

To do so, the data gathered was coded in the form of time series and then compared with the aid of a time-series processing system (for a detailed description of the theoretical and practical aspects of this method, see Guercin, 1990, and Guercin, Roussey \& Piolat, 1990).

A time series is defined here as a set of data ordered in time. Each point in time in a series is called an instant. For each instant, there exists a corresponding complex event composed of the modalities taken on by the various qualitative variables at that instant. In addition to other operations, the computer system compares the global structure of any two time series. It then computes normalised distance as a function of editing distance (Wagner \& Fisher, 1974). In the present study, this normalised index is called distance.

To measure the improvement made by the revisers, each text (experimental, expected, and actually produced) was coded in the form of a time series in which statements are attributed a sequence number. To determine whether the revisers' procedures corresponded to our hypothetical strategies, the latter were coded in the form of model time series. The model time series represented the step-bystep ordering of the corrections made in application of the two functional principles defined. For each instant, three variables were used: two variables to code the exact identity of the linguistic element moved, and one variable to code the location in the text where the writer was working.

Due to the particularities of the verbal material and the experimental procedure used, each of the three hypothetical strategies could be expressed in concrete form by three or four model time series. These time-series variants were necessary due to differences in how certain aspects of the verbal material were processed, 


$\begin{array}{lrrrrrrrrrr}\text { Instants } & 1 & 2 & 3 & 4 & 5 & 6 & 7 & 8 & 9 & 10 \\ & & & & & & & & & & \\ \text { Experimental text } & 1 & 2 & 9 & 6 & 4 & 5 & 3 & 8 & 13 & 7 \\ \text { Expected text } & 1 & 2 & 3 & 4 & 5 & 6 & 7 & 8 & 13 & 9\end{array}$

Figure 1 Time series of the experimental and expected texts

Each number $l$ to 8 corresponds to the ranks of the statements in the basic text. The 9 corresponds to the added statement. The 13 indicates the end of processing in the text area.

\begin{tabular}{l|rrrrrrrrrr} 
& T instants & 1 & 2 & 3 & 4 & 5 & 6 & 7 & 8 & 9 \\
J variables & & & & & & & & & & \\
$L$ & & 4 & 4 & 2 & 2 & 2 & 4 & 2 & 4 & 2 \\
$I$ & & 1 & 2 & 9 & 3 & 4 & 3 & 5 & 4 & 7 \\
$D$ & & 2 & 2 & 15 & 3 & 4 & 15 & 5 & 5 & 7
\end{tabular}

Figure 2 Time series of the Simultaneous Strategy. The set $J=(L, I, D)$ are the indexes of the three experimental variables, $L, 1$, and $D . L=$ Linguistic Level of the text segment manipulated $(4=$ within-statment, $2=$ between-statement $) . I=$ Identification of the moved element. Each number corresponds to an element (word, group of words, statement) that may or may not be moved. For statements: 1 to $9=$ rank of the statement in the expected text; $0=$ other. For words: $1,2,8=$ words to be permuted; $3=$ word to be deleted; $4=$ word to be added; $9=$ other. $D=$ Destination. Location of the element after it is moved. This number is the rank of the statement in the text as it stood when the manipulation was made (statement order changes every time a statement is moved). The 15 is used for the save area. The rank of each instant orders each manipulation in the set of all manipulations:

1. move 'filet' to another location within statement 2;

2. move 'ballon' to another location within statement 2;

3. move statement 9 into the save area;

4. move statement 3 to position 3 ;

5. move statement 4 to position 4 ;

6. move 'nageoire' to the save area;

7. move statement 5 to position 5;

8. move 'fille' into statement 5 ;

9. move statement 7 to position 7 .

and did not alter the application of the functional principles. The distance between any two time series in a given set was minimal, whereas the difference between the sets was marked. The three hypothetical strategies were thus coded by distinct sets of model time series.

\section{Results}

\section{Did the writers improve the texts they were given to revise?}

To answer this question, it was first necessary to compute the distance between the time series of the to-be-revised experimental texts and those of the expected texts (narrative and description). This distance was equal to 0.50 for both text 
types. If the distance between the time series of the expected text and that of the text produced by the subject was less than the 0.50 cut-off point, then the text was considered to have been improved.

The data obtained indicated that $92.6 \%$ of the subjects improved the experimental text, even if only slightly. Only one of the 48 adults and seven of the 48 children did not improve the text's quality. The extent of the improvement varied significantly by age $(\mathrm{F}(1 / 88)-13.85, \mathrm{p}<0.001)$ and degree of expertise $(F(1 / 88)=49.64, p<0.001)$ regardless of the type of text (see Figure 3$)$. The more expert adults performed particularly well, producing texts that were much closer to the expected texts than the less expert adults (description: $\mathrm{d}(\mathrm{E}+)=0.10$ vs $\mathrm{d}(\mathrm{E}-)=0.36$; narrative: $\mathrm{d}(\mathrm{E}+)=0.10$ vs $\mathrm{d}(\mathrm{E}-)=0.32 ; \mathrm{F}(1 / 44)=31.5$, $\mathrm{p}<0.001)$. The less expert children made essentially ineffective corrections; their descriptions (description: $\mathrm{d}(\mathrm{E}-)=0.44)$ and even their narratives (narrative: $\mathrm{d}(\mathrm{E}-)=0.43$ ) were far removed from the expected text. Expert children performed much better on narratives (narrative: $\mathrm{d}(\mathrm{E}+)=0.13$ ) than on descriptions (description: $\mathrm{d}(\mathrm{E}+)=0.33 ; \mathrm{F}(1 / 44)=4.29, \mathrm{p}<0.05)$.

These findings confirm the assumption that the knowledge of text schemas required to perform this task is mastered to differing degrees by different subjects. Adults, who know text structures better than children, manage to correct them better. Children do not master the schematic organisation of descriptions as well as they do narratives, especially the less expert ones, whose performance is particularly poor. Their ability to diagnose problems and make corrections is clearly less well developed for descriptions.

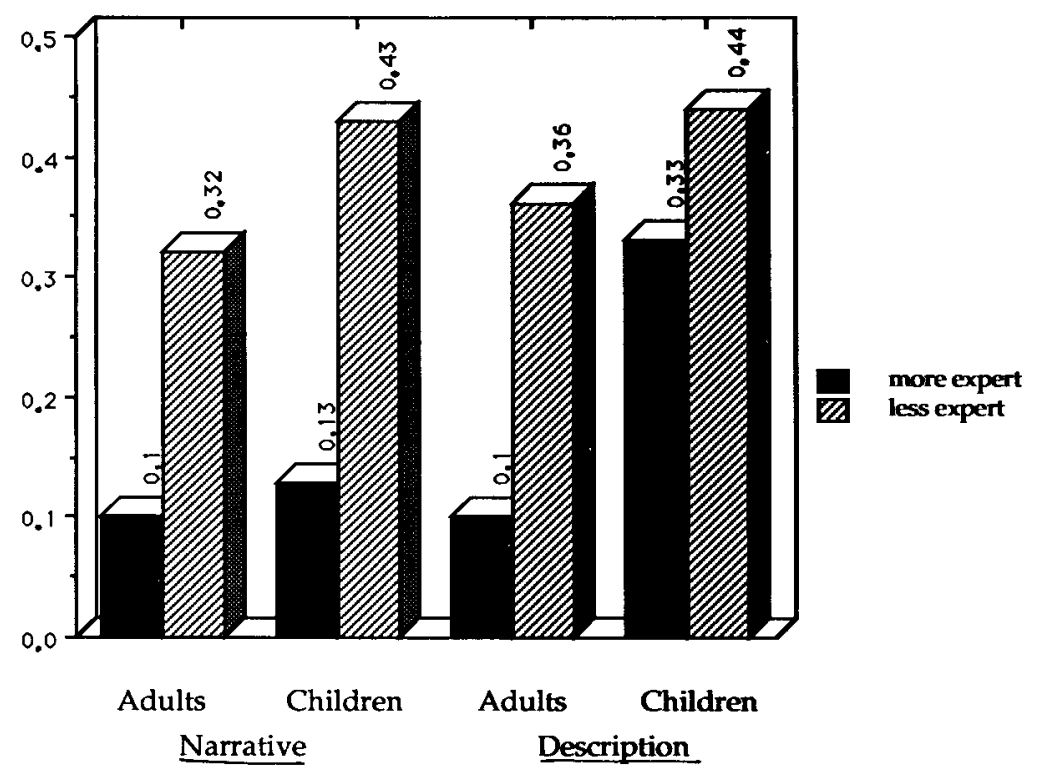

Figure 3 Mean distances between the time series of the expected texts and the produced texts by text type, subject age and degree of expertise. 
2. Did the revisers use the hypothetical strategies?

In order to determine whether the revisers actually implemented one of the hypothetical strategies, the distances between the model time series and the time series produced by each subject were computed.

By definition, a model time series leads to the production of the expected text. Thus, only those subject time series produced for texts that were the same as or very similar to the expected text were compared $(0<$ distance from expected text $<0.2)$. The time series of 32 adults (E+: 22, E-: 10) and 20 children (E+: 17, E-: 3) were thus examined. The correction ordering mode of non-expert children could not be analysed.

When one of the model time series was the closest to the time series produced by a subject (i.e. the distance from that model was shorter than from the other sets), the subject was considered to have employed the corresponding strategy. Out of the 52 subjects having improved their text, only 28 could be characterised as such. The results are given in Table 1 .

The Global-then-Local Strategy (GLS) was used by only two adults. The Simultaneous Strategy (SS) was used by more expert adults than expert children (Ad.E $+=9 / 21$ vs Ch.E $+=1 / 22$; Fisher Test: $\mathrm{p}=0.01$ ) and non-expert adults (Ad.E- $=1 / 10$; Fisher Test: $p=0.06$ ). Expert adults used the Simultaneous Strategy (SS) more often to revise the narrative than the description (narrative $=$ $7 / 10$ vs description $=2 / 12$; Fisher: $\mathrm{p}<0.025$ ).

For the narrative, more expert adults than expert children used the Simultaneous Strategy (Ad.E $+=7 / 10$ vs Ch.E $+=0 / 11$; Fisher: $p<0.005$ ). For the description, the adults most often revised the text using the Local-thenGlobal Strategy (LGS: 4 experts and 2 non-experts). Only two expert children could be attributed a strategy on the description.

The adults improved the narrative by revising the linearly step by step so as to filter and solve all the diagnosed problems one after another, regardless of the linguistic level to which they pertained. To improve the description, however, most adults went through the text several times, processing the statements in order and alternately focusing on different levels. For both text types, the adults did not find it useful to improve the overall structure of the text if the statements themselves were syntactically and semantically unacceptable.

The children, even the expert ones, were not able to re-establish the proper structure of the description, which they seemed not to know very well, and no revising strategies could be attributed to them. Although expert children master the narrative superstructure well enough, they were not able to focus simultaneously on two linguistic levels in order to improve the narrative. They began by correcting within-statement errors.

It should be noted here that the correction ordering modes defined for the hypothetical revising strategies were only applied by a limited portion of the population studied (28 out of 52). Perhaps one or both of the functional principles upon which these strategies were based should be questioned. 


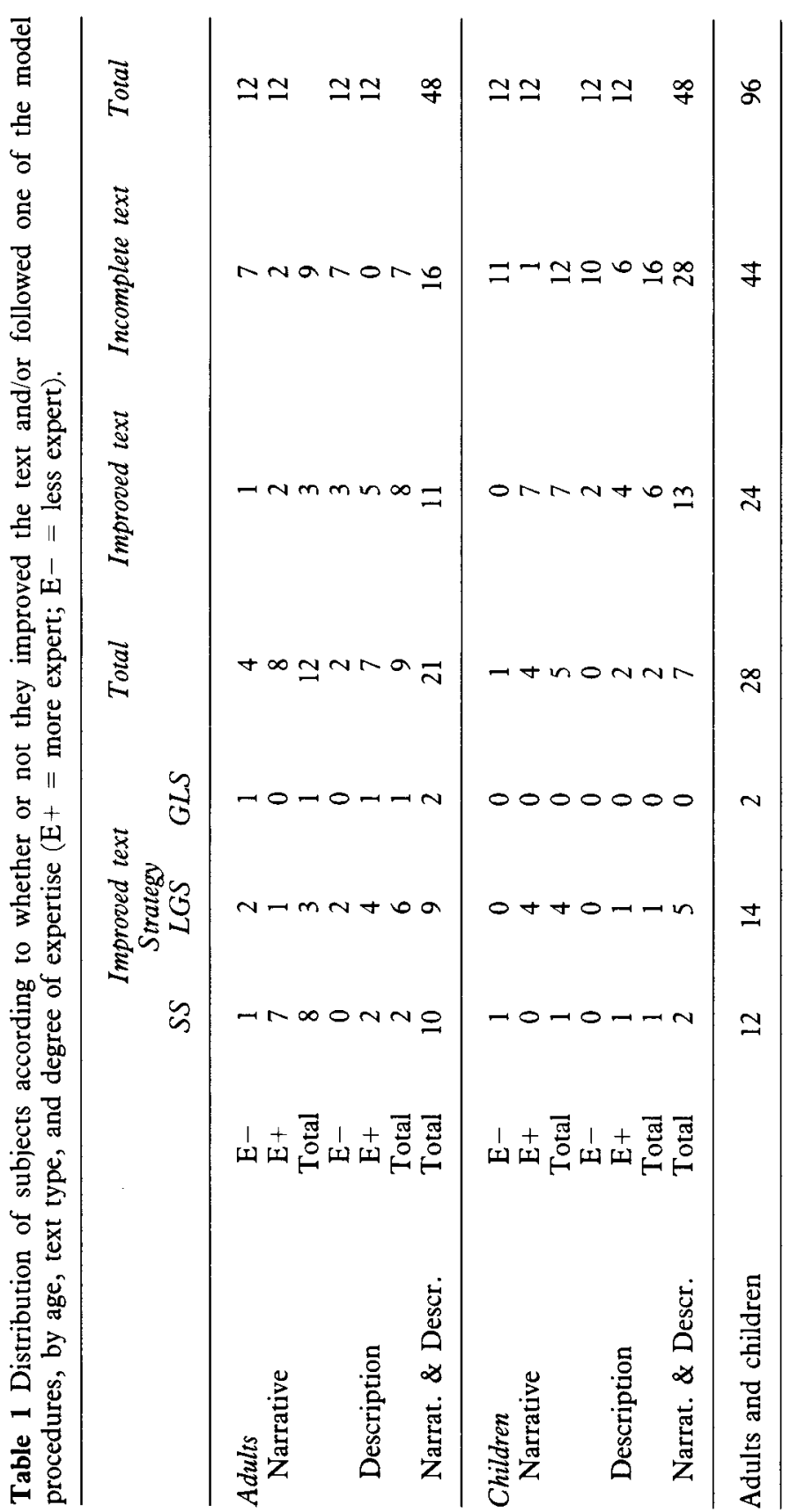


3. Were the functional principles applied?

The time series representing the locations where the subjects made corrections can be used as an indicator of whether the subjects (both those who did and those who did not manage to improve the text) applied the principle of in-order processing. Analysis of consecutive pairs in this time series indicated that on the average for all 96 subjects, the second element in the pair was greater than the first in $75 \%$ of the pairs. This percentage is high if we consider that on the average, the revisers began correcting on the third statement (mean rank of the first correction $=3.75$ ) and therefore they must necessarily have gone back in order to revise statement 2 (where the first error occurred). Thus, whatever their age or degree of expertise, and regardless of the type of text being revised, subjects progressed through the text in a linear fashion. They revised the statements in their order of occurrence, even if it meant going through the text several times to correct all the linguistic problems that might appear at any point during the revision process.

As to the linguistic levels processed by the revisers, the time series of most of the 96 subjects involved operations at both of the experimentally perturbed linguistic levels. Only 8 of the 96 revisers worked on one level only (1 non-expert adult writer for the narrative; 5 non-expert children, 3 for the description and 2 for the narrative; 2 expert children, one for each type of text). In cases where corrections were made at both text levels, the subjects who did not succeed at improving the text and did not use one of the strategies studied here (36 out of 44) generally alternated between revision at different levels.

\section{Discussion}

The results obtained indicated three distinct groups of subjects in the population studied: those who managed to improve the text as expected using one of the strategies defined, those who improved the text without using one of the strategies, and those who were not able to effectively transform the text. The results for these three groups will be discussed one at a time, while stressing the effect of the experimental factors.

Subjects who improved the text by using one of the model strategies

In the first group, the more expert subjects, whether adult or child, were virtually the only ones to order their corrections using one of the procedures defined for two of the three revising strategies (SS and LGS). To use such strategies, they must have had (a) the knowledge needed to define the task, set a goal, and establish crtieria (text schema, syntactico-semantic structure of statements, etc.) and (b) the knowledge required to operate (means-ends table, ordering procedures, etc); and these two types of knowledge must have been efficiently actualised. However, such actualisation was different at different ages and for different text types. 
A ge and the narrative text

To improve the narrative text, the children and adults did not use the same revising strategy, although subjects in both of these groups have the knowledge relevant to this type of text schema (Fayol, 1985; Stein \& Glenn, 1982). Their differing choice of strategies indicates either that children and adults do not have the same skills, that they actualise them in a different manner, or that children are not able to focus on two linguistic levels at once. Further investigation is therefore necessary in order to find out whether 10-year-olds have several strategies available that they are not yet able to apply due to the cognitive overload such strategies entail (for example, difficulty focusing on two linguistic levels), or whether they only have one available procedure. Developmental research should enable us to determine the origins of and criteria by which children and adolescents acquire new skills likely to increase the number of available revising strategies. Remember also that the global strategy was virtually not used here. Preferring to eliminate the easy, local problems first (well-defined diagnosis and highly accessible means-ends table), these revisers did not focus directly on the aspects of overall text organisation without having done the necessary local 'clean-up'.

\section{Type of text and adults}

The results obtained for this group of revisers raise the question of whether the strategies defined are adequate, and whether they can be extended to different text types. Indeed, expert adults did not use the same revising strategies on narratives and descriptions. We can assume that these revisers chose the most appropriate strategy for the type of text being corrected; thus the Simultaneous Strategy may be particularly efficient and appropriate for revising narratives, whose structure is highly sequential. The statements in the narrative could indeed only be ordered in one way. However, this difference in operating procedure may be due to a differing degree of mastery of the text schemas. Descriptions are perhaps more difficult to revise because descriptive text improvement plans may not be as easy to devise as narrative text improvement plans. Adults may begin with revision based on a rough plan of the text as a whole, refining this plan as they progress through the task. The surface aspects of the text would then be corrected first. The Simultaneous Strategy may only be used or usable for all types of texts by particularly skilled writers capable of clearly anticipating the final product.

\section{Subjects who improved the text without using a model strategy}

To interpret the results obtained for the revisers who did not order their corrections as predicted in the model procedures while still transforming the text in the expected way (mainly adults and expert children), the control conditions necessary to the completion of the chosen procedure might be questioned. Indeed, it cannot be postulated that these revisers did not use any strategy whatsoever for lack of either type of knowledge. The results indicate, first of all, that these revisers were able to correct the texts completely, and secondly, that they applied the functional principles underlying the procedures that correspond to the revising 
strategies defined. We should therefore invoke the way in which these revisers control the actualisation of the procedure implemented to carry out the revising task. This ongoing, top-down control, which we hypothesise to be strategically defined right from the beginning of the task, may be poorly executed if the reviser does not manage to maintain it throughout revision due to the diverse problems encountered in the text (bottom-up control). Matsuashi and Gordon's findings (1985) support this type of explanation. In this study, the authors showed that corrections were of a higher quality when revisers proposed modifications without looking at their composition, that is, without relying on textual 'data'. This fully enabled them to reformat the text by means of top-down control without interference by bottom-up control. Thus, in the task studied here, fluctuations of top-down control in the application of a strategy may lead to correction ordering procedures that are different from the ones formalised here. For example, while a reviser is focusing on one of the two linguistic levels (using a consecutive strategy, LGS or GLS), he/she may detect and resolve some problem at another level that turns out to be more imposing, thus abandoning the initial approach before going through the entire text.

In addition to this problem of intermittent control in the application of a revising strategy, it can also be hypothesised that these revisers, though experts for the most part, have difficulty diagnosing the problems to be processed. Thus in order to be sure they have eliminated all of the errors in the text, they repeatedly apply their strategy on several passes through the text. This makes their correction ordering time series far removed from the model time series. It is not necessary to consider that these subjects used other strategies than those formalised here, since no regularity in the order of their corrections could be found.

\section{Subjects who failed to improve the text}

Finally, the revisers who were not able to clearly improve their text no doubt did not set an improvement goal for the text as a whole. It can also be hypothesised that they did not co-ordinate the two functional principles that they do in fact have available (i.e. in-order processing, and at least consecutive if not simultaneous focusing on two linguistic levels) so as to form a usable strategy, and thus a skill.

In conclusion, we would like to suggest that comparison of revisers' productions by means of the a priori generation of hypothetical, highly precise performance models based on clearly defined functional principles is a particularly fruitful approach to describing and understanding the complexity of the text-revising task. This hypothetico-deductive method does not, however, allow us to account for all of the constraints with which learning writers must cope in more natural text improvement situations. Nevertheless, the results obtained clearly indicate to teachers that in order to help their students, they must (a) take the cognitive overload of their young revisers into account, and (b) encourage them to determine the knowledge necessary to set sub-goals for the revising task, and particularly the knowledge needed to define the task or to make a revising plan. 


\section{References}

Bastien, C. (1987) Schèmes et stratégies dan l'activité cognitive de l'enfant. Paris: Presses Universitaires de France.

Beaugrande, de R. (1984) Text Production: Toward a Science of Composition. Norwood, NJ: Âblex.

Blaye, A. (1988) Confrontation socio-cognitive et résolution de problème (à propos du produit de deux ensembles). Thèse de Doctorat d'Université, Université de Provence, Aix en Provence.

Daïute, C. (1986) Physical cognitive factors in revising: insights from studies with computers. Research in the Teaching of English 20,141-59.

Faigley, L. and Witte, S.P. (1981) Analyzing revision. College Composition and Communication 32, 400-14.

Fayol, M. (1985) Le récit et sa construction. Une approche de Psychologie Cognitive. Paris: Delachaux \& Niestlé.

Fayol, M. and Gombert, J.E. (1987) Le retour de l'auteur sur son texte: bilan provisoire des recherches psycholinguistiques. Repères 73, 85-95.

Flower, L. and Hayes, J.R. (1981) Plans that guide the composing process. In C.H. Frederiksen and J.F. Dominic (eds) Writing: The Nature, Development and Teaching of Written Communication (pp. 39-58). Hillsdale, NJ: Erlbaum.

Guercin, F. (1990) Un langage formel pour le traitement des chroniques. Thèse de Doctorat d'Université, Université de Provence, Aix en Provence.

Guercin, F., Roussey, J.Y. and Piolat, A. (1990) Time series: A tool for analyzing complex cognitive activities. Applicaton to the study of text revising strategies. Cahiers de Psychologie Cognitive/European Bulletin of Cognitive Psychology 1, 79-110.

Hayes, J.R. and Flower, L. (1980) Identifying the organization of writing processes. In L.W. Gregg and E.R. Steinberg (eds) Cognitive Processes in Writing (pp. 3-30). Hillsdale, NJ: Erlbaum.

Hayes, J.R., Flower, L., Schriver, K., Stratman, J. and Carey, L. (1987) Cognitive processes in revision. In S. Rosenberg (ed.) Advances in Applied Psycholinguistics: Reading, Writing and Language Learning (pp. 176-240). Cambridge: Cambridge University Press.

Matsuashi, A. and Gordon, E. (1985) Revision, addition, and the power of the unseen text. In S.W. Freedman (ed.) The Acquisition of the Written Language: Response and Revision (pp. 226-49). Norwood, NJ: Ablex.

Piolat, A. (1988) Le retour sur le texte dans l'activité rédactionnelle précoce. European Journal of Psychology of Education 3, 449-60.

-(1990) Vers l'amélioration de la rédaction de texte. Dossier d'habilitation à diriger des recherches. Aix en Provence: Université de Provence.

Piolat, A., Farioli, F. and Roussey, J.Y. (1989) La production de texte assistée par ordinateur. In G. Monteil and M. Fayol (eds) La psychologie scientifique et ses applications (pp. 177-85). Grenoble: Presses Universitaires de Grenoble.

Piolat, A., Roussey, J.Y and Farioli, F. (1987) Révision de texte par l'enfant et l'adulte en production assistée par ordinateur. Bulletin d'A udiophonologie 3, 733-48.

Piolat, A., Roussey, J.Y. and Guercin, F. (1988) Stratégies de révision de textes par des enfants de 10 ans et des adultes. Paper presented at colloque de la section de psychologie expérimentale de la S.F.P. 'Automatisme et contrôle', Dijon, 29-30 January.

Scardamalia, M. and Bereiter, C. (1983) The development of evaluative, diagnostic, and remedial capabilities in children's composing. In M. Martlew (ed.) The Psychology of Written Language (pp. 67-95). New York: Wiley.

Stein, N.L. and Glenn, C.G. (1982) Children's concept of time: the development of a story schema. In W.J. Friedman (ed.) The Developmental Psychology of Time. New York: Academic Press.

Van Dijk, T.A. (1984) Macrostructures sémantiques et cadres de connaissances dans la 
compréhension du discours. In G. Denhière (ed.) Il était une fois... compréhension et souvenirs de récits (pp. 49-84). Lille: Presses Universitaires de Lille.

Wagner, R.A. and Fisher, M.J. (1974) The string-to-string correction problem. Journal of the Association for Computing Machinery 1, 168-73.

Witte, S.P. (1985) Revising, composing theory, and research design. In S. Warshauer Freedman (ed.) The Acquisition of Written Language: Response and Revision (pp. 250-84). Norwood, NJ: Ablex.

Appendix

Narrative

Basic text

Dans un bassin deux dauphins commencent un numéro. Après quelques sauts ils se renvoient un ballon par dessus un filet. Soudain le ballon tombe en dehors du bassin. Cette maladresse va interrompre le spectacle. Mais une fille court après le ballon et l'envoie aux dauphins. Les dauphins récupèrent le ballon rejeté dans l'eau. Ainsi ils peuvent reprendre le numéro. Le spectacle finit bien.

Experimental text

Dans un bassin deux dauphins commencent un numéro. Après quelques sauts ils se renvoient un filet par dessus un ballon. La mouette a un petit bec jaune. Les dauphins récupèrent le ballon rejeté dans l'eau. Cette maladresse va interrompre le spectacle nageoire. Mais une court après le ballon et l'envoie aux dauphins. Soudain le ballon tombe en dehors du bassin. Le spectacle finit bien.

fille/robe écossaise/Ainsi ils peuvent reprendre le numéro

Description

Basic text

Le dauphin est un mammifère marin. Son corps allongé et gris ressemble à celui d'un requin. Sa tête se prolonge en un grand museau appelé rostre. Sa bouche a une centaine de dents pointues. Le dauphin intelligent apprend à jouer avec l'homme. Il saisait un bâtom que lui tend de dresseur. Il saute très haut à travers un cerceau. Il pousse des ballons dans un filet.

\section{Experimental text}

Le dauphin est un mammifère marin. Son requin allongé et gris ressemble à celui d'un corps. La mouette nettoie ses plumes. Il saisait un bâton que lui tend le dresseur. Sa bouche a une centaine de pointues. Le dauphin intelligent apprend à jouer avec l'homme nageoire. Sa tête se prolonge en un grand museau appelé rostre. Il pousse des ballons dans un filet.

dents/robe écossaise/Il saute très haut à travers un cerceau/ 